\title{
روح العولمة وأخلاق المستقبل
}

\section{طه عبد الرحمن*}

ليست "العولميات" صناعتي ولا "المستقبليات" هوايتي، وإنما صناعتي وهوايتي الأخلاقيات، وهي حاضرة بقوة فيهما معا، وهذا الحضور هو وحده الذي يعنيني هاهنا، لا سيما وأن الأخلاق هي الشرط الذي لا يستقيم بدونه شيء، لا عولمة ولا مستقبل ولا غيرهما: وحسبي الإشارة إلى أن ما أريق من مداد وسيق من كلام عن "العولمة" في مختلف بقاع العالم، على قصر أمدها، لم يسبق له نظير، حتى كأن كلماها لا تنفد وحركاتا لا تنتهي؛ ولولا أني خشيت أن أخل بواجبي في تدارك نقص شنيع شاب ما كتب عنها باللسان العربي، لما اشتغلت بهذا الموضوع لفرط نفوري مما يُملى عليّ ويندفع فيه الناس، وشدة عزوفي عما لا يصدر عني وأتفرد به، كأني أتوجس من ورائه كيدَ عقول ماكرة وتآمر إرادات خفية؛ وليس هذا النقص الشنيع إلا تناسي التقويم الأخلاقي لهذه الظاهرة الهائلة، اللهم إلا ما كان من إشارات هنا وهناك تَرِد في سياق تحليل اجتماعي أو ثقافي لها أو في سياق مقارنة بينها وبين الإسلام؛ وأريد هنا أن أشتغل بجانب من هذا التقويم الأخلاقي، عسى أن ينفتح لي فضاء فكري إسلامي يتسع للإشكالات الأخلاقية للعولة.

\section{ما هي العولمة في روحها؟}

في البدء، أحتاج إلى وضع تعريف للعولمة يُقرّب معناها على أساسه أباشر هذا التقويم الأخلاقي، لكني أريد أن أمهد له باطلاعكم على بعض المبادئ التي آخذ بها في عموم تفكراتي -أو تأملاتي - في موضوع الأخلاق، وأذكرها

لكم مطبَّقةً على العولمة، وهي أربعة:

مبدأ عموم الأخلاق: مقتضاه أن كل الأفعال التي يقوم بها الإنسان، كائنة ما كانت، هي في حقيقتها، أفعال خُلُقية، ذلك أن الغرض من كل فعل يصدر عنه هو أن يحقق به إنسانيته، فيرفعها درجة أو يخفِضها درجة؛ وتحقيق الإنسانية، رفعا لما أو خفضا، هو بالذات ما يُسمّى في الاصطلاح "أخلاقية" أو "تخلّقاًّ؛ وعلى هذا، فكل فعل يأتي به الإنسان يكون سببا في تخلقه، على هذا التخلق قد يزيد أو ينقص بحسب طبيعة هذا الفعل؛ ومن هذه الأفعال، 
على سبيل المثال، ما يقوم به أرباب العولمة، فهم، على ما يظنون، يسعون إلى تحقيق مزيد التقدم للإنسانية؛ والتقدم هو عبارة عن الانتقال من حال إلى حال أفضل منه، فيكون تخليقا.

مبدأ الممة الإنسانية: مقتضاه أن الإنسان بعزيمته أقوى من الأمر الواقع وأصلب من حتمية الحدث، لأن الواقع القائم لا يستنفد أبداً الإمكان الذي في يد الإنسان ولا أن الحتمية المنسوبة إلى التاريخ تفوق طاقته؛ فمثلاً إذا قيل بأن العولمة أمر محتوم لا مفر لسكان العالم من احتماله، قلنا بأن الإنسان، متى استنهض همثه، أضحى بمقدوره أن يدفع عنه هذا الأمر أو يغير مجراه بوجه من الوجوه، وإلا فلا أقل من أن يتعامل معه بوصفه خياراً حضاريا غير ملزم له في كليته.

مبدأ التحدي المناسب: مقتضاه أن الإنسان يلقى في كل زمان من التحديات ما يناسب قدره وطاقته، مع العلم بأن لكل زمان نموذجه البشري؛ فإذا اختلفت التحديات باختلاف الأزمنة، فإنها لا تختلف من حيث تناسبها مع أقدار النماذج البشرية المقارنة لهذه الأزمنة؛ فمثلاً إذا قيل بأن العولمة تشكل تحديا للإنسان لا عهد للتاريخ به، قلنا إن كنتم تقصدون بقولكم إن العولمة تتحدى الإنسان اليوم بما لم تتحد به سابق التحولات الكبرى إنسان الأمس، فهو قول مردود، لأن لكل زمان تحدياته المناسبة له، وإن كنتم تقصدون أن التحدي الذي تأتي به العولمة هو على قدر الإنسان الحديث كما كانت سابق التحولات على قدر سابق النماذج البشرية، فهو قول مقبول ولا غبار عليه.

مبدأ خروج النقيض: مقتضاه أن الشيء، متى بلغ أقصى نفوذه، استصحب وجوده خروج نقيضه أو خرج هو نفسه إلى هذا النقيض - أي ينقلب إليه؛ فالعولمة، مثلاً، تبتغي أن تندرج المجتمعات البشرية قاطبة في سيرورتا، وهو غاية ما يمكن أن يطمع فيه أرباها؛ فكان أن برزت إلى الوجود تكتلات قومية وعرقية ودينية تنافح عن هويتها وخصوصيتها كما في دول أوروبا الشرقية، بل أخذت تنشأ في الدولة نفسها التي تسوق قاطرة العولمة، أي الولايات

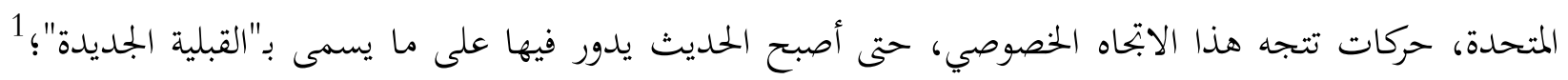
وها قد بدأت تلوح في الأفق، لا عولمة كاسحة واحدة بترف العالم كله، وإنما عولمات متعددة: "عولمة أمريكية" و"عولمة أوروبية" و "عولمة آسيوية"؛ ولِرَ لا يجوز أن نتصور "عولمة إسلامية" ولو على المدى البعيد؟!

1

Bauman, Zygmunt. Postmodern Ethics. New York: Blackwell, 1993, P 141. 
ينتج من هذه المبادئ الأربعة أن العولمة ظاهرة تخلّق للإنسان عادية مَثُلُها مثل سابقتها من الظواهر التاريخية التي تقلبت على الإنسان عبر مختلف أطواره، فأصاب منها بقدر ما أصابت منه، وسوف تمضي كما مضى غيرها ويبقى الإنسان كما بقي إلى أجل مسمى.

بعد فراغي من ذكر المبادئ الأساسية لفكري الأخلاقي، أمضي إلى بيان التعريف الذي أرتضيه هاهنا للعولمة. تعريف العولمة: اعلمْ أن تعريفات العولمة أكثر من أن تحصى، وهذه الكثرة دليل على أهما ظاهرة معقدة وغير محددة، بحيث يعسر حتى الآن على الباحثين وضع تعريف مفصّل يحيط بجميع مكوناتها وتقتنع به أغلبيتهم، لذلك، لن أنقل عن غيري تعريفاً لما، وإنما أضعه من عندي مراعياً أمرين: أحدهما، أن الإجمال فيه يغني عن النفصيل؛ والثاني، أن الاعتبار الأخلاقي فيه أولى من غيره؛ وصيغة هذا التعريف هي التالية:

العولمة هي السعي إلى تحويل العالم إلى مجال واحد من العلاقات -أو قُل مجال علاقي واحد- عن طريق تحقيق سيطرات ثلاث: "سيطرة التقنية في حقل العلم" و"سيطرة الثبكة في حقل الاتصال" و"سيطرة الاقتصاد في حقل التنمية".

تلزم من صيغة هذا التعريف نتائج ثلاث؛ النتيجة الأولى هي أن العولمة ليست حالة للعالم، وإنما فعل فيه، ولا هي فعل منتِه، وإنما فعل مستمر.

والنتيجة الثانية أن أثر هذه الفعل المستمر هو توحيد العلاقات أو الارتباطات داخل العالم، بمعنى أن هذا العالم يصير نطاقاً اجتماعيا واقتصاديا وسياسيا وثقافيا واحدا يؤلف بين أفراد البشرية كافة؛ وقد طاب لبعض الدارسين والهيئات أن يعبروا عن هذا التأليف بتشبيهات طارت في الناس كل مطار، فقالوا: "القرية الكونية" و"المدينة الكونية" و"المجتمع الكوني" و "الجوار الكوني"، ولِّر لا "البيت الكوني"؟! والعلاقات في هذا الإطار الموحد ليست، كما قد يسبق إلى الفهم من لفظ "التوحيد"، على شكل واحد، وإنما على أشكال مختلفة، ولا هي مصورة في مستوى واحد، وإنما متسعة لمستويات عدة، ولا هي باقية على حالة واحدة، وإنما متقلبة على الدوام؛ فسمة العلاقات في هذا النطاق العالمي الواحد هي التشابك بلا انتهاء والتزايد بلا انقطاع، فالوحدة المتوحدة للنطاق تجتمع إلى الكثرة المتكاثرة 
أما النتيجة الثالثة فهي أن الوصول إلى هذا التشابك المتزايد في العلاقات مع حفظ وحدة مجالها يتم بواسطة تحصيل سيطرات ثلاث هي: "سيطرة التقنية" و"سيطرة الشبكة" و"سيطرة الاقتصاد"؛ وأحتاج الآن إلى أن أبين من جهة أولى كيف أن كل سيطرة منها تسهم في بناء هذا المجال العلاقي الواحد للعالم، ومن جهة ثانية كيف أن نمط العلاقات الذي تأتي به هذه السيطرة يؤثر في أخلاق المرتبطين بهذا النمط.

\section{سيطرة التقنية في مجال العلم}

معروف أن مفهوم "التقنية" يقابل مفهوم "النظرية"، ومعروف أيضاً أن الإطار الذي ترد فيه النظريات هو الذي اختص باسم "العلم"؛ ووجه التقابل بين التقنية والعلم هو أن الأولى تعد معرفة مطبقة والثاني يعد معرفة مجردة؛ وملا كانت التقنية تطبيقاً للعلم، لزم أن تكون تابعة له وخادمة لأغراضه، فتكون له الأسبقية عليها.

لكن هذا التصور التقليدي للتقنية والعلم بات غير مقبول في سياق العولمة، حيث إن العلاقة بينهما أضحت علاقة تداخل قوي تأخذ التقنية بزمامه؛ فبعد أن كانت وسيلة في يد العلم صار العلم وسيلة في يدها تزوده بآفاق جديدة في البحث، مستنبطة من خصائصها الاستعمالية ونتائجها التحويلية، كما توجهه بحسب الحاجات الاستهلاكية التي تحددها السوق العالمية أو بحسب المشاريع التجارية التي تضعها كبريات الشركات المتحكمة في هذه

ثم إن المعرفة التقنية أخذت تتضمن، إلى جانب دراسة مختلف الآلات والأدوات، دراسة السياق الصناعي والاجتماعي والثقافي الذي يتم فيه تطبيقها، رابطة بين التقدم التقني وبين تطور البنيات الاجتماعية وتفاعلها مع بيئتها الطبيعية؛ بمعنى أن المعرفة التقنية صارت تشتغل بما كان يختص العلم النظري بالاشتغال به، مما زاد من قدرتا على

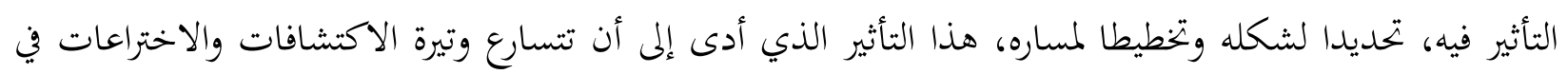
مختلف مجالات المعرفة، حتى أصبح بعضها يثير أشد المخاوف والمخاطر على مستقبل البشرية.2 2 
وهكذا، أضحى استعمال لفظ "العلم" وحده يضيق عن إفادة المراد منه، ويستدعي أن نشير إلى ازدواجه بالتقنية، فنقول: "العلم التقاني" بدل "العلم" وكذا بالنسبة للشعب العلمية التي تندرج تحته، فنقول مثلاً: "الاتصال التقاني" بدل "الاتصال" و "الاقتصاد التقاني" بدل "الاقتصاد".

وإذا نحن تأملنا في طبيعة العلاقات الكونية التي يمكن لهذا الوضع التقني للعلم أن ينشئها بين البشر، وجدنا أها علاقات يطبعها الحساب والتجريب؛ وهذا يعني أن العلاقات التي تسعى العولمة إلى إنشائها بين الأفراد والمجتمعات في مشروعها التوحيدي علاقات ذات صبغة إجرائية صريحة؛ ومعلوم أن الإجراء هو كل فعل آلي، أي فعل نتحكم في مدخله ومخرجه معا؛ والمفهوم الذي يضاد مفهوم "الإجراء" هو "العمل"، لأن العمل يأخذ بمقصد الشيء قبل أن يباشر التحكم فيه، والمقصد عبارة عن مخرج للشيء يجاوز مدخله كما يجاوز مقصد حفظ الحياة، مثلاً، مبدأ الصيام في يوم مرض؛ وعلى هذا، فلا مكان لمعنى "العمل المقصدي" في العلاقات الكونية التي تنتجها تبعية العلم للتقنية؛ فأهل العولمة في علاقاقم التقانية يفعلون ولا يعملون ويحكمون ولا يقصدون، فأخلاقهم من هذه الجهة أخلاق الواقعين في تقديس للعلم والتقنية أشبه بتقديس علم الإله الذي لا يُحد، وما الفتنة التقانية التي نراها من حولنا إلا شاهد على هذا التأليه للتقنية!

\section{سيطرة الشبكة في حقل الاتصال}

مذ كان الإنسان وهو يركب وسائل الاتصال ليبلغ غرضه في الاجتماع، مبتدئا باستعمال الوسائل الطبيعية التي وجدها بين يديه، ثم تعاطى لصناعة وسائل من عنده، حتى انتهى إلى اختراع ما يعرف بـ"شبكات الاتصال"، وتمثل نموذجها الأول في شبكة الإبراق الكهربائي؛ ولا يهمنا هنا حدث الشبكة بقدر ما تممنا الكيفية التي تعاملت بها العولمة مع هذا الحدث لكي تصنع مجالا علاقيا واحدا للبشرية جمعاء، ذلك أن هذه الكيفية تقوم في الانتقال من العمل بالشبكة الاتصالية الجزئية - أو الخاصة - إلى العمل بالشبكة لاتصالية الكلية - أو العامة؛ فبعد أن كانت شبكات الحاسوب تقتصر على مؤسسات وإدارات مخصوصة ومتفرقة، تََّّ وصْلُ هذه الشبكات بعضها ببعض بواسطة الخيوط الهاتفية، واستمر التوسع في هذا الوصل عبر العالم كله بالاستعانة بالأقمار الصناعية؛ ونتج عن هذا الوصل المتزايد شبكة جامعة واحدة يوشك المشتركون فيها أن يبلغ عددهم المليار تعرف باسم "الإنترنت"؛ وكان لا بد لهذا التحول في الاتصال من أن ينعكس أثره على صناعة الحاسوب نفسها، فتحصل فيها، بفضل البحوث المتواصلة التي 
يُشرف وتُنفق عليها الشركات المتنافسة، تطورات مذهلة على مستوى العتاد والبرججة، تطورات لم يلبث معها الاتصال والحاسوب أن أخذا في الاندماج بينهما على مستوى أنظمتهما.

وإذا نحن نظرنا في طبيعة العلاقات الكونية التي يمكن هذا الوضع الشبكي الكلي للاتصال أن ينشئها بين بني البشر، وجدنا أنه مكّن من جمع المعلومات المختلفة وخزنها بفعالية بالغة، ثم نقلها وتناقلها بين المستهلكين في كل مكان بسرعة متناهية وبأقدار غير محدودة، حتى بدا هؤلاء وكأفم يؤلفون عشيرة واحدة تستهلك معلومات واحدة؛ لكن لو دققنا النظر في هذا الوضع الاتصالي الهائل، لتبين لنا أن العلاقات بين رواد هذه الشبكة الأم ليست بالتداخل المنطور ولا بالتقارب المظنون، ولا هي بالأولى من جنس العلاقات التي تجمع بين أهل القرية الواحدة.

وبيان ذلك أن الذي تنقله الشبكة ليس إلا مضمونات يتلقاها المتلقي أو يلقي بها الملقي في شكل إشارات ضوئية متوالية نسميها "معلومات"، بحيث يحصل التفاعل، لا مع مصدريها الآدميين، منتجين أو موزعين، وإنما مع الآلات التي تنقلها؛ ثم إن هذه المعلومات تسبح في بحر من الإعلانات، حتى اقترن اسم "الإعلام" باسم "الإعلان"، وأضحت المعلومة عبارة عن "معلومة مُعلنة"، لا "معلومة معلومة"؛ فهاهنا صفتان للمعلومة تمنعان من قيام تواصل حقيقي بين ذوات "الشبكيّين" على منوال التواصل بين ذوات المواطنين، وهما: "الشكل الإشاري" و"السياق الإعلاني"؛ فالإشارة الضوئية هي صورة رمزية لا حياة فيها، وواضح أنه لا تواصلَ بغير حياة، ثم الإعلان الإعلامي هو صورة بتحارية لا بترُرّد فيها، وواضح أنه لا تواصلَ بغير بترّد.

والمفهوم الذي يضاد "القول المعلوم" أو "المعلومة" هو "القول المعروف" أو قُله "المعرفة" -قياسا على "معلومة"، لأن الأصل في الشيء المعروف هو أن يتم إدراكه بنفسه، لا بصورته، ومن باب أولى لا برمزه، فإذن أهل العولمة في علاقاتم الاتصالية يُعلنون ولا يخلصون ويَعلمون ولا يعرفون، فأخلاقهم أخلاق الواقعين في تقديس المعلومة بما يشبه تقديس كلام الإله؛ وما الفتنة المعلوماتية التي نشهدها بين أظهرنا إلا دليل على هذا التأليه للاتصال! 


\section{سيطرة الاقتصاد في حقل التنمية}

من البداهة القول بأن الاقتصاد عامل حاسم في التنمية، وليس دونه بداهة القول الآخر وهو أن الاقتصاد في الغرب تقلب في أطوار رأسمالية مخصوصة، لكن الذي يقِلُّ عنهما بداهة هو أن يقال بأن العولمة تسعى إلى إلباس كل أنواع التنمية لباس التنمية الاقتصادية الرأسمالية، أي إدخالها في سياق المبادلات التجارية الحرة، حتى إنه يجوز الكلام هذا الصدد عن واقع "التسلط الاقتصادي"؛ فقد حصل الاقتناع مع مطلع العولمة بأن الاقتصاد خيّرٌ في أهدافه وخير في وسائله وأن النمو الاقتصادي أسبق وأفضل نمو ممكن كما أن رفعه إلى أقصى غاية لا يمكن إلا أن يأتي منه أرفع تقدم للشعوب قاطبة، بحجة أنه يزيد في الإمكانات ويخلق الوظائف ويحل المشاكل في خختلف المستويات الاجتماعية، فضلاً عن أنه ينضبط طبيعيا بقوانين تقرّب الفقراء من الأغنياء كقانون "التوافق الطبيعي للمصالح"، ومقتضاه أن مصالح الناس الشخصية تدفعهم إلى توزيع رأس المال على مختلف الوظائف بما يقترب أقصى ما يمكن مما تتطلبه المصلحة العامة، وكذا قانون "مفعول التساقط"، ومقتضاه أن تزايد غنى الأغنياء يلغي على التدريج فقر الفقراء لما ينطوي عليه هذا التزايد من أسباب الاستثمار والتشغيل، وحتى الفروق بين الفئتين تكون مقبولة، بل مشروعة متى كانت تنفع في نماء الثروة الذي سيستفيد منه الجميع؛ ودعما لهذا المنطق الرأسمالي، أطلقت العولمة يد الشركات العملاقة التي تستثمر وتُسوِق حيثما شاءت وكيفما شاءت لا يحدها وطن ولا سيادة كما أقامت مؤسسات قوية تضمن لهذه الشركات مزيد النفوذ والسلطان كالبنك الدَّولي وصندوق النقد الدولي ومنظمة التجارة العلمية.

وفي هذا المضمار، واضح أن العلاقات الكونية التي ينشئها هذا التسلط الاقتصادي في مجال التنمية، لا يككن أن تكون إلا علاقات المصلحة المادية الخالصة؛ فإذا غدت الشركات الخارقة لحدود الأوطان هي التي تتكفل بالتنمية ين هذه الأوطان، فمعلوم أن هذه الشركات لا تعمل إلا بمبدأ السوق بلا قيد والتنافس بلا شرط والربح بلا حد في سياق عالمي لا وجود فيه لمجتمع مدني عالمي ولا لمؤسسات ذات سلطة يمكن أن تعاكس هذا التسيب الاقتصادي، حتى إن هذه الشركات لا تتورع في التحايل على القوانين وممارسة الضغوط وإرشاء الميئات والأشخاص لبلوغ أغراضها في رفع القيود عن الأسواق والأموال والأعمال وبسط كامل سلطاها على الشعوب وبث قيمها المادية في النفوس؛ وهل نستغرب بعد هذا أن تتفشى هنا وهناك الرشوة وتضعف الهمة ويقل التضامن وتذهب المواطنة وتنتشر الجريمة ويكثر الشذوذ ويسود المخدِّر؟! 
والمفهوم الذي يضاد مفهوم "التنمية" هذا هو "التزكية"؛ فإذا كانت المصلحة في التنمية هي عموم المنفعة المادية التي تلبي حاجة الإنسان، فإنه في التزكية يُشترط فيها أن يَصلُح بها حاله، سواء أكانت منفعة مادية أم منفعة معنوية، 3 ولا صلاح لهذا الحال بغير زيادة في إنسانيته، بمعنى أخلاقيته؛ أما المنفعة المادية التي يمكن أن تلبي الحاجة ويحتمل أن تُفسد الخُُقُق، فإن التزكية تصرفها صرفا؛ فالتزكية، على خلاف التنمية، لا تطلب عموم المنافع، وإنما تطلب المصالح منها، أي المنافع التي يكون بها صلاح الإنسان؛ فإذن أهل العولمة في علاقاقم الاقتصادية ينفعون ولا يُصلحون ويُنمُون ولا يُزَُون، فأخلاقهم أخلاق من وقعوا في تقديس الاقتصاد بما يشبه تقديس أفضال الإله، وما الفتنة الاقتصادية التي ابتُلي بها الجميع إلا ناطقة بهذه التأليه للاقتصاد!

يتلخص لنا من بيان السيطرات الثلاث التي تحكم بنية العولمة والتي تورّثها فِتَنا ثلاثا أن هذه السيطرات تعرّضها لأزمة أخلاقية مثلّثة، وتتمثل هذه الأزمة أولا في كون سيطرتا التقانية تحصرها في نطاق الفعل الإجرائي، ولا تخرج بها إلى نطاق العمل المقصدي، وثانياً في كون سيطرها الاتصالية تحصرها في نطاق المعلومات البعيدة، ولا تخرج بها إلى نطاق المعروفات القريبة، وثالثاً في كون سيطرتا الاقتصادية تحصرها في نطاق المنفعة المادية، ولا تخرج بها إلى المصلحة المعنوية؛ فإذن السؤال الذي يواجهنا الآن هو كيف يمكن الخروج من هذه الأزمة الأخلاقية المثلثة؟ فهم نختاج إلى إبداع أخلاق جديدة؟ وهل في طاقة العولمة أن تمدنا بهذه الأخلاق؟

\section{تقويم الاعوجاج الأخلاقي للعولمة}

أحقية الإسلام بتقويم الاعوجاج الأخلاقي للعولمة: الملاحظ هو أن هذه الأزمة الأخلاقية تلتها بالفعل يقظة أخلاقية خاصة، وبتلت هذه اليقظة في مظاهر شتى، منها تقوية تدريس مواد الأخلاق وإحداث كراسي لها في المعاهد والجامعات وعقد المؤتمرات والمناظرات حول الإشكاليات الأخلاقية المستجدة؛ ومنها أيضاً إنشاء لحجن الحكماء ووضع دساتير أخلاقية وتأسيس حركات إصلاحية ومنظمات إنسانية؛ ومنها كذلك فتح أبواب في علم الأخلاق غير مسبوقة ووضع نظريات فيه غير معهودة، فجرى الخوض في أخلاقيات الحياة وأخلاقيات البيئة وأخلاقيات الإعلام وأخلاقيات

$$
\begin{aligned}
& 3 \\
& 4
\end{aligned}
$$


الإدارة وأخلاقيات الشغل وأخلاقيات الأعمال والمقاولة، كما اتسعت الدعوة إلى ضرورة أن يتحمل الإنسان المسؤولية إزاء كل بجالات الحياة، وأن يسارع إلى تحصين نفسه بالأخلاق اللازمة لمواجهة التلوث في الطبيعة والتسيب في التقنية والتفكك في المجتمع والفساد في السياسة والتضليل في الخَبر.

ومع هذا كله، ما زال العالم يتردى في أخلاقه وما زال الإنسان في كل مكان يشتكي من سوء حاله، وما ذاك إلا لأن النظام الاقتصادي الاتصالي التقاني الجديد استطاع، لصلابة بنيانه وقوة ذكائه، أن يستوعب هذه المطالب والحاجات الأخلاقية ويسخرها لخدمة مصالحه ولاستمرار قانونه الأبدي الذي هو كسب المال بلا قدر؛ فأصبحت المقاولة هي الغاية بَدَل أن تكون الوسيلة، وأصبحت الأخلاق وسيلةً في يدها تتوصل بها إلى أغراضها على بصيرة من أمرها؛ وإذا صح هذا صح معه أن الطريق إلى الخروج من هذا التردي لا يمكن أن يأتي على يد من كانوا سببا فيه، أهل اقتصاديات كانوا أو أهل معلومات أو أهل تقنيات، فأين إذن نلتمس الأخلاق التي تقدر على مواجهة آفات هذا النظام الكاسح وتقويم اعوجاجاته لفائدة البشرية؟

\section{الجواب أنه لا بد لمذه الأخلاق أن تستوفي على الأقل شروطا ثلاثة:}

الشرط الأول هو أن تكون مستمدة من خارج هذا النظام، وإلا اقتدر على احتوائها وتحويلها لخدمة مشاريعه

كما أسلفنا ذكره.

والشرط الثاني هو أن يكون مصدرها أقوى من مصدره، حتى يحصل الانقياد لها، فتمكن من التأثير فيه وتوجيهه إلى خدمة الصالح العام.

أما الشرط الثالث فهو أن تكون أخلاقا كونية، لا محلية، حتى توافق مقتضاه الذي هو إيجاد مجتمع كوني واحد.

ولا نحتاج إلى كبير تأمل لكي نتبين أنه لا سلطة يمكن أن تستوفي هذه الشروط إلا سلطة الدين، فالدين المنزل هو وحده الذي لم يفرزه هذا النظام، بل هو الذي أفرز بعض قيم هذا النظام على ما دخل عليها من شبهات، وهو وحده الذي شرّعه المنزَّه عن مشابهته شيئاً، ثم هو وحده الذي جاء للناس كافة ودعا إلى وحدة الأقوام وجعل لكثير منهم ثقافة واحدة؛ وليس عجبا أن تقع الهرولة إلى حمى الدين حيث كان يظن أن العولمة قد استأصلته كما في الدول 
الغنية، فقد تيقن المهرولون من أنه لا عاصم اليوم من طوفان العولمة إلا سفينة الوحي الإلهي؛ وإذا كان الأمر كذلك، هل ينبغي أن يرجع كل قوم إلى ما وجدوا عليه آباءهم من دين، فيقتبسون منه أخلاقا يدفعون بها شرور العولمة أو، على العكس من ذلك، ينبغي أن يجتمع سادة الأوام كلها، فينظروا في أدياهم ويستنبطوا منها ما يتفق عليه جميعهم، ويكون هذا المتفق عليه هو الأخلاق التي يتصدَّون بها لأضرار العولمة كما دعا إلى ذلك بعضهم فيما بات يسمى بـ

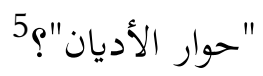

أجيب على هذا السؤال المزدوج بالنفي مع القطع، فعندي أنه لا يعلُّد الأخلاق يقهر العولمة ولا قدر مشترك منها يقهرها؛ فالأول -أي تعدد الأخلاق - لا يقهرها، لأن الكل لا يضاهيه إلا الكل، والعولمة كلّ بجتمع، والأخلاق المتعددة أجزاء متفرقة، ولا قدرة للمتفرق على المجتمع؛ والثاني -أي قدر مشترك من الأخلاق - على فرض أنه من الممكن حصوله لا يقهرها هو أيضاً، لأنه لا يزيد عن كونه قدرا أدنى من الأخلاق، والقدر الأدنى لا حول له مع العولة؛ والحق أنه لا يكفي في تقويمها إلا القدر الأعلى من الأخلاق، ولا يكون ذلك إلا في دين واحد مأخوذ به في كليته، فإذن أي دين هذا الذي يقدر على العولمة ولا تقدر عليه؟

الجواب لا غبار عليه؛ إنه دين الإسلام وليس غيره؛ ودليلي على ذلك أسميه ب"دليل الزمن الأخلاقي"؛ وتفصيله

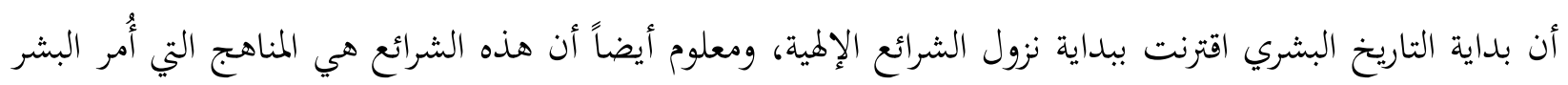
باتباعها في ضبط سلوكهم الاجتماعي وتحقيق وجودهم الحضاري؛ وإذا كان الأمر كذلك، جاز أن نرتب أطوار هذا التاريخ بحسب هذه الشرائع، فننزها منزلة أزمنة أخلاقية تختلف باختلاف الشرائع، فيكون الزمن الأخلاقي هو الطور الذي يبتدئ عند ظهور الدين وينتهي عند ظهور غيره متى وُجِد؛ فمثلاً الزمن الأخلاقي المسيحي يبتدئ بانتهاء الزمن الأخلاقي اليهودي وينتهي بابتداء الزمن الأخلاقي الإسلامي؛ تترتب على هذه النتائج الثلاث التالية:

أولاها، أن الأزمنة الأخلاقية ليست درجة واحدة، وإنما درجات بعضها فوق بعض يكون فيها الزمن الأخلاقي اللاحق أعلى رتبة من الزمن الأخلاقي السابق، إذ يطويه ويزيد عليه؛ فمثلاً الزمن الأخلاقي المسيحي يعلو على الزمن الأخلاقي اليهودي والزمن الأخلاقي الإسلامي يعلو على الزمن الأخلاقي المسيحي، وهو أعلاها جميعا، لأنه الدين

KÜNG, Hans: Projet d'éthique planétaire, La paix mondiale par la paix enre les religions 
الخاتم؛ ومعنى هذا أن التخلق الإنساني يتجه إلى تحقيق الكمال الإنساني وأن التقلب في الأطوار يتقدم بهذا التخلق إلى هذه الغاية، وهي لا تتحقق إلا في الزمن الأخلاقي الإسلامي وحده.

والثانية، أن كل فعالية إنسانية حصلت في طور تاريخي ما، ينبغي أن تنسب إلى الزمن الأخلاقي الذي يمثله هذا الطور، سواء وافقت شريعته أو خالفتها، بمعنى أن أهل كل زمن أخلاقي يكونون مسؤولين عما يحدث في زمافم حتى ولو أتى به من أبى أن يتخلق بأخلاقه؛ فيكون المسيحي مثلاً مسؤولاً عما صنعته في زمانه يد اليهودي؛ ولا ينفع أن يقال بأن المسؤولية لا تقع إلا على الفاعل، ذلك لأن الفاعل التاريخي على ضربين: الفاعل المباشر -أو القريبالذي قام عيْنا بالفعل، والفاعل غير المباشر -أو البعيد- الذي تسبب تقديرا في الفعل بتمهيد الظروف لحصوله كأن يكون الواحد منا مسؤولا، لا عن نفسه ولا عن جيله فحسب، بل أيضاً مسؤولاً عن غيره والأجيال التي تأتي من بعده؛ والمسؤولية التي يتحملها أهل الزمان الأخلاقي عن أفعال غير منضبطة بشريعته انضباطا مباشرا هي من صنف المسؤولية البعيدة.

والثالثة، أن العولمة فعل حضاري يكصل في الطور التاريخي الذي نجتازه الآن والذي هو بالذات الزمن الأخلاقي الخاص بالدين الإسلامي، فإذن يتعين أن ننسبها إلى هذا الزمن دون غيره؛ وعليه، يجوز أن نقول بأن العولمة ظاهرة إسلامية وإن لم تكن من صنع أيادي المسلمين أنفسهم وكانت من صنع أيادي غيرهم؛ يلزم من هذا أن كل مسلم معاصر مسؤول عن العولمة ولو لم يكن صانعها، لأن الزمن الأخلاقي زمنُه هو دون سواه؛ وتفريغ ذمته من هذه المسؤولية يوجب عليه أن يبادر إلى تعقّب مظاهر العولمة وتفحّص إمكانات التخلق التي تحملها، فإن كانت هذه الإمكانات تزيد في التخلق أخذ بها وحث عليها، وإن كانت تَنُقص من هذا التخلق استنهض همته في دفعها والتحذير منها، وإن كانت لا تزيد في التخلق ولا تنقص منه، خُيرّ فيها، إن شاء أخذ بها وإن شاء دفعها.

وبعد أن ظهر أن الإسلام هو الدين الذي يملك المشروعية والمقدرة على تقويم اعوجاج العولمة، فلنوضح الآن كيف يمكنه أن يمارس هذا التقويم على مظاهرها السيطرية الثلاث: "المظهر التقني" و "المظهر الشبكي" و"المظهر الاقتصادي".

6 وابواب على الاعتراض بالآية الكريمة: "تلك أمة قد خلت لها ما كسبت ولكم ما كسبتم" (البقرة: 134)، أي ما كسبت في زمافا الأخلاقي وكسبتم في زمانكم الأخلاقي. 
ينطلق هذا التقويم من تصحيح مفهوم "العالم" المتداول عند أرباب العولمة، فليس العالم بجالاً واحدا من العلاقات مع إطلاق مدلول "العلاقة" كما يتصورون، وإنما هو مجال واحد للعلاقات مع تقييدها بكوها حُلقية، أي أن العالم هو بجال علاقي أخلاقي؛ ذلك أنه لما كانت أفعال الإنسان، كما تقدم، أفعالاً خلقية صريحة، كان لا بد أن تتجه هذه الأفعال إلى غيهر باعتباره إنساناً، أي كائنا أخلاقيا، بمعنى أن التعامل الذي يكصل في دائرة أفراد البشرية جمعاء هو تعامل أخلاقي؛ ثم لما كانت هذه الدائرة هي التي يُطلق عليها اسم "العالم"، صار العالم -وليس ما دونه كالمجتمع أو القبيلة- هو المجال الأصلي الذي يدور فيه الفعل الخلقي، بحيث يكون لكل فرد فيه واجبات أخلاقية نحو غيره كما يكون لغير واجبات أخلاقية نحوه؛ فإذن الطبيعة الأخلاقية للأفعال الإنسانية بتعل صاحبها مسؤولا في الأصل إزاء العالم كله، وليس إزاء بعضه فحسب، مجتمعاً كان أو جماعة أو أسرة؛ وبعد هذا التصحيح، يصير مدلول "العولمة" هو أها السعي إلى تحويل العالم إلى مجال واحد من العلاقات الأخلاقية؛ أمضي الآن إلى بيان كيف ينهض الإسلام بتقويم الاعوجاج الذي دخل على المظهر السيطري الأول للعولمة، وهو "المظهر التقني"، أي بيان كيف ينتقل هذا الدين الخاتم بالعلم من رتبة الإجراءات التي هي مجرد أفعال تقنية إلى رتبة الأعمال التي هي عبارة عن أفعال أخلاقية.

\section{المبادئ الإسلامية لتقويم الاعوجاج الأخلاقي للعولمة}

مبدأ الاعتبار: اعلمْ أن هذا الانتقال يتم بفضل مبدأ معرفي أساسي يأخذ به الإسلام، وهو "مبدأ الاعتبار"؛7 ومقتضاه الإجمالي أن العلم النافع لا يكون إلا بالنظر في حكمة الشيء قبل سببه وفي مآله قبل حال؛ وتفصيل ذلك في أصلين اثنين؛ الأول أن الاعتبار نظر في الحكمة: النظر الاعتباري غير النظر الإجرائي، إذ النظر الإجرائي نظر في العلل السببية، بينما الاعتبار نظر في العلل الحِكمية؛ وفرق بين سبب الشيء وحكمته، فالسبب هو الفعل الذي يُحدث أثراً يسمى "مسنَّبا"، بينما الحكمة هي المقصد الذي كان من وراء هذا الفعل، وهو بالأساس قيمة خُلقية؛ والأصل في السبب أن يَبقى تأثيره على وجه واحد، بينما الأصل في الحكمة أن تناسب المقام، لأخها الوجه الذي يتقرر به العمل بالشيء؛ فالمعتبِر هو من لا يقتصر في العمل على إدراكَ الأسباب، بل يجاوزها إلى إدراك الحِكم التي تقارغا

الآية الكرية: "القد كان في قصعهم عبرة لأولي الألباب، ما كان حديثًا يفترى ولكن تصديق الذي بين يديه وتفصيل كل شيئ، وهدى ورمة لقوم

يؤمنون" (يوسف: 111) - (111).

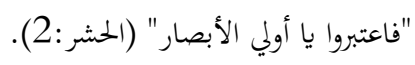


ويمليها المقام، حتى إذا اهتدى إليها جعل الأسباب تابعة لها، فإن وافق سبب الشيء حكمتَه عمل به، وإن خالفها ترك العمل به.

وهكذا، يتضح أن المعرفة في سياق النظر الاعتباري تُقِِّّد العمل بأسباب الأشياء بالعمل بالقيم الحلقية التي تنطوي عليها هذه الأشياء، ومن ثم تخرج عن أن تكون جملة إمكانات تقنية قد تنفع أو تضر كما هو الشأن في النظر الإجرائي لكي تصبح إمكانات عملية تنفع ولا تضر.

والثاني بالاعتبار نظر في المآل: معلوم أن لكل فعل حالا ومآلاً، علما بأن الحال هو حاضر الفعل والمآل هو ما ينتهي إليه من آثار إن آجلا أو عاجلاً، إلا أن من الأفعال ما قد تكون فيه هذه الآثار قريبة ويمكن توقعها وضبطها،

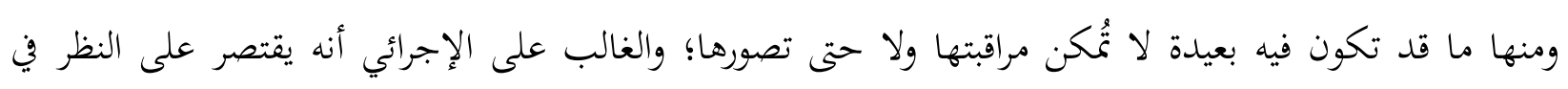
الحال دون المآل، بل قد يُقدم على الفعل وهو على تمام الوعي بأنه يجهل مآله؛ بينما القاعدة في الاعتبار هي الوقوف

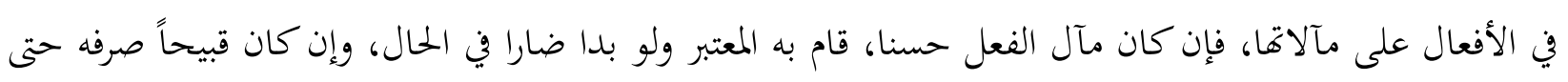
ولو بدا نافعا في الحال.

وعلى هذا، فإن المعيار الذي تأخذ به المعرفة في سياق النظر الاعتباري هو المآل، فتكون مقبولة إذا ظهر أن مآلها يعود بمزيد التخلق ومردودة إذا ظهر أنه يعود بنقصانه، على خلاف النظر الإجرائي الذي لا يرى فيها إلا جملة إمكانات تقنية ينبغي الانتقال بها إلى حيز التطبيق، مقرراً أن التطبيق هو وحده الكفيل بأن يدلنا على المآل. ومتى التخذت المعرفة هذا الطريق الذي يُقدّم الحكمة على السبب ويقدم المآل على الحال، اقتضت حدودا وضوابط لا نظفر بها في مجال الإجراءات التقنية ويأتي على رأس هذه الحدود والضوابط أن لا نندفع في تطبيقات العلوم إلا بالقدر الذي يعود بالنفع على الناس، على خلاف ما نراه في حاضر الإجراءات التقنية، حتى أضحى راسخاً في العقول أن الخير كلّه في العلم والثقنية.

وبهذا، يتبين أن مبدأ الاعتبار الإسلامي يقضي بأن نجعل حدا لهذه الهرولة الشديدة إلى التطبيقات التقنية

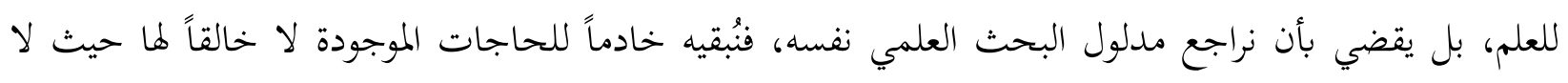
توجد، وخاضعاً لقانون المقاصد والمآلات، لا لمنطق الأسباب والأحوال وحده. 
فلننعطف الآن على توضيح كيف ينهض الإسلام بتقويم الاعوجاج الذي دخل على المظهر السيطري الثاني للعولمة، وهو "المظهر الاتصالي"، أي توضيح كيف ينتقل هذا الدين الخاتم بالاتصال من رتبة المعلومات التي هي مجرد منتوجات شبكية إلى رتبة المعروفات التي هي عبارة عن ثمار أخلاقية؟

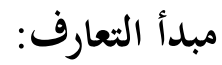

اعلم أن هذا الانتقال الثاني يحصل بفضل مبدأ تواصلي جوهري يقره الإسلام، وهو "مبدأ التعارف"؛ ومقتضاه الإجمالي أن التواصل السليم لا يكون إلا بكلام طيب بين متكلمين كرماء؛ وتفصيل ذلك في أصلين اثنين:الأصل الأول أنه لا تعارف بغير معروف: ذلك أن التعارف غير الاتصال (المعلوماتي)، فالاتصال تواصل خبري، لا اعتبار فيه للقيمة الخلقية، في حين أن التعارف تواصل خبري لا ينفك عن القيمة الخلقية المحمودة؛ ومعلوم أن الشيء ذا القيمة الخلقية المحمودة هو الذي جرى الاصطلاح عليه باسم "المعروف"، أي "الخيرٌ" الذي تعارف عليه الناس جميعاً، وقيل: "قول معروف"، أي قول فيه خير؛ فالتعارف يكون مبنياً أصلاً على معرفة هي عبارة عن إدراك لمعروف معين؛ لذا، سميت هذه المعرفة "عرفاناً" وسمي نقيضها "نكراناً"، في حين أن المعرفة في الاتصال (المعلومات)، تسمى "علماً" ويسمى نقيضها "جهالا"؛ وشتان بين العلم والعرفان (=العلم بالمعروف) وشتان بين الجهل والنكران (=الجهل بالمعروف).

وهكذا، يلزم في سياق التعارف أن يكون في الخبر المنقول بوجه من الوجوه معروفاً -أي خيرًا- كما يلزم أن يجد فيه المتلقي نفعا يَصلح به حُلُقهه، بحيث يصير تناقل الأخبار بين الملقي والمتلقي عبارة عن تناقل لخيرات وطيبات؛ ومن ثم، تخرج الأخبار عن كوها بجرد معلومات قد تضر أو تنفع إلى مقام الكلمات الطيبات، أي إلى ما يمكن أن نسميه

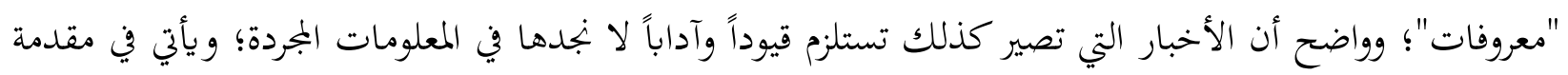
هذه القيود والآداب أن لا نجمع ولا نولّد ولا نختزن إلا ما كان يأتي بالخير لمتلقيه على عكس ما نراه في حالة المعلومات، حتى طارت في الناس عبارة "انفجار المعلومات".

8 الآية الكريعة:

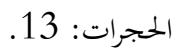

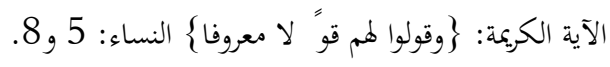


ومن هنا يتبين أن مبدأ التعارف الإسلامي يقضي بأن نجعل حدا لهذا التسابق المحموم من أجل الظفر بأكبر قدر من المعلومات، وأن نُرجع المعلومة إلى وضعها الظريف المحدود، حتى لا تنقلب على الإنسان، فتُلقي به في مَهلكة قد تكون شرا من مهلكة أسلحة الدمار الشامل، أليست تقتل الروح وسلاح الدمار لا يقتل إلا الجسم! أما الأصل الثاني فهو أنه لا تعارف بغير اعتراف: لما كان الخبر الوارد في التعارف هو بمنزلة معروف ينفع المتلقي، اقتضى أن يبادله هذا المتلقي بمعروف مِثله؛ وتكون هذه المبادلة بأن يبدي إقراره بالمعروف الذي جاءه، وإقرارَ بفضل صاحبه عليه -إذ أحاطه بما لم يكن في علمه وأمده بما لم يكن في مِلكه- ثم بأن يعمل على أن يزوده بمعروف مما عنده؛ وهذا يعني أن العلاقة التي سوف تقوم بين الملقي والمتلقي علاقة أخلاقية لا غبار عليها؛ وحينئذ، ينفتح لهم طريق المعاملة بالحسنى وتنشأ بينهما روابط الاحترام والانفتاح والتسامح والتعاون والتقارب والتوادد؛ وقد يتنافسان في ذلك، حتى يفضل بعضهما بعضا، لأنه تنافس في التخلق، والتخلق ليس له حد يقف عنده؛ فإذا زاد عند أحد المتنافسَين كان أكرمهما، وإذا نقص كان دون ذلك كرماً.

تم متى اعترف المتلقي بفضل الملقي عليه من جهة تزويده بما لم يكن يعرفه، فإنه يكون قد أقر في ذات الوقت بأن هذا الملقي قد استقى خبره من مقام ليس كمقامه أو من سياق ليس كسياقه ولو أفما قد يشتركان في أمور غير قليلة، فضلاً عن اشتراكهما في الأصل الإنساني الواحد، بحيث تكون فائدة الخبر على قدر هذا الاختلاف في المقام أو السياق؛ وإقرار المتلقي بهذا الاختلاف إنما هو في نهاية المطاف إقرار بالتمبيز الثقافي أو بالخصوصية الحضارية للملقي؛ وعلى قدر هذا التميز أو الخصوصية تكون حاجتهما إلى مزيد التواصل والتعاون، حتى يتعرف كل منهما على ما عند الآخر مما يتفرد به من دونه.

وهكذا، يظهر أن مبدأ التعارف الإسلامي يقر بالثفاوت الأخلاقي بين المتعارفَين، لأنه ثمرة الثنافس على حفظ العلاقة الأخلاقية التي بتمعهما، كما أنه يقر بالاختلاف الثقافي بين المتعارفَين، لأنه سبب في توسيع دائرة معارفهما، بينما الاتصال المعلوماتي يلغي كلياً عنصر الأخلاق في المعلومات ويعمل على محو هذا الاختلاف لصالح ثقافة الملقي 
وأخيراً لنوضح كيف ينهض الإسلام بتقويم الاعوجاج الذي دخل على المظهر السيطري الثالث للعولمة، وهو "المظهر الاقتصادي"، أي لنوضح كيف ينتقل هذا الدين الخاتم بالاقتصاد من رتبة توفير المنافع المادية إلى رتبة تحقيق المصالح الخلقية؟

\section{مبدأ ابتغاء الفضل}

اعلم أن هذا الانتقال يحصل بفضل مبدأ تعاملي أساسي يقره الإسلام، وهو "مبدأ ابتغاء الفضل"؛10 ومقتضاه الإجمالي أن الاقتصاد الصالح لا يكون إلا بتكامل المقوم المادي مع المقومات الأخرى للتنمية وباتصاله بالأفق الروحي، وتفصيل ذلك في أصلين اثنين:الأصل الأول ابتغاء الفضل طلب للتخلق: اعلم أن "ابتغاء الفضل" في الإسلام غير مطلق "التجارة" في اقتصاد السوق، إذ التجارة في هذا الاقتصاد عبارة عن أفعال البيع والشراء بجردة من الاعتبار الخلقي، في حين أن أفعال البيع والشراء في "ابتغاء الفضل" تكون مقرونة بهذا الاعتبار الخلقي؛ وبيان ذلك أن لمفهوم "الفضل" وجهين حُلقيين أساسيين لا نظير لمما في مفهوم "السلعة" أو "البضاعة"، أحدهما، اشتقاقه من نفس الأصل الذي اشتق منه لفظ "الفضيلة"، والثاني دلالته عل معنى "الخير"؛ فالفضل ليس عموم الخير؛ تتفرع على هذا المدلول حقيقة أساسية، وهي أن السلعة، في سياق ابتغاء الفضل، تكتسي قيمة خلقية، فضلاً عن قيمتها التجارية، إذ تُعد خيراً يُنتفع به خُلقيا ومعنوياً، فضلاً عن الانتفاع به مالياً ومادياً، بحيث تستوعب إخضاع قوانين السوق لقواعد السلوك الثابتة؛ ومتى أضحت السلعة خيراً صريحاً، أمكن ائتلافها مع أنواع الخير الأخرى التي لا تكون سلعاً، إذ الخير لا يعارض الخير؛ وحينئذ، يتغير مدلول "التنمية الاقتصادية"، إذ تصير عبارة عن تزكية حقيقية: "تزكية للمال" و "تزكية للحال"؛ وكل تنمية اقتصادية هذا وصفها، من شأها أن تجتمع إلى غيرها من ضروب التنمية الأخرى وتتكامل معها في الارتقاء بالإنسان وخَلْق وسط عالمي سليه.

أما الأصل الثاني فهو ابتغاء الفضل طلب للتقرب: لا يختلف "ابتغاء الفضل" في الإسلام عن "بتارة السلع" في اقتصاد السوق من جهة أن المدلول الأخلاقي لا ينفك عنه، وهي منفكة عنه فحسب، بل أيضاً من جهة أن الفضل 
في الإسلام يُنسب إلى المتفضل الأسمى جل وعلا ويتقترن باسمه، 11 وهي غير منسوبة إليه ولا مقترنة باسمه؛ وفي هذه النسبة والاقتران غور بعيد نقف منه على لطيفتين اثنتين: إحداهما أنه لا شيء يَشعر فيه الإنسان بالملكية شعوره هما وهو يقتني بضاعة، نظراً لاشتغال جميع جوارحه ومداركه بها؛ ومعلوم أنه ليس في الآفات شر على الإنسان من الآفات التي يستتبعها الشعور بالملكية، ابتداءً من ادعاء الاختصاص بالشيء وانتهاء بادعاء الربوبية؛ فحيئذ، تكون نسبة ما يقتنيه الإنسان إلى المتفضل الأسنى تنبيها له على أنه هو المالك الحقيقي، وعلى أن امتلاكه هو له ليس استحقاقاً، حتى لا ينجر إلى البغي والطغيان، وإنما تكرماً منه سبحانه عليه، حتى يتصرف فيه بما يقربه إلى حضرته؛ واللطيفة الثانية، أنه لا شيء يبدو أوغل في المادية إيغال السلعة فيها، نظراً لدوران المال عليها وقربها من لمس الإنسان، والمال والملموس قمة المحسوس؛ ومعلوم أنه ليس في الأشياء أبعد عن الأفق الروحي من المادة؛ فعندئذ، تكون نسبة ما يقتنيه الإنسان إلى المتفضل الأسنى تنبيها على أن المعنى الروحي يداخله على ظاهر بعده عنه كما يداخل ما ليس بسلعة، وعلى أن الإنسان مطالب بأن يتبين هذا المعنى ويقف عليه، حتى يتقرب به إلى مولاه؛ وفي هذه الحال، تغدو التجارة، لا تبادلَ سِلع تستنفد قيمتَها في الاستهلال المادي كما هو الشأن في اقتصاد السوق، وإنما تبادل أفضال تعرج بالمستهلكين إلى الأفق الروحي.

وهكذا يتبين أن مبدأ ابتغاء الفضل الإسلامي يجعل القيم الأخلاقية والروحية في صلب عملية التنمية الاقتصادية، بحيث لا تكون هذه التنمية نافعة ولا مشروعة إلا إذا سعت إلى تحقيق هذا المقصد الخلقي والروحي، ومتى خالفته وجب مراجعة النظر فيها، بل تركها إلى تنمية أخرى، لأها ليست مقصدا في ذاهما، وإنما وسيلة إلى مزيد التخلق، واعتبار الوسيلة يسقط بسقوط اعتبار المقصد.

وجاء الأوان لأن أختم عرضي، ملخصاً ما بسطته في معرض تقويمي الأخلاقي للعولمة انطلاقا من المنطور الإسلامي، فأقول بأن العولمة، في روحها، فعل حضاري متواصل يتجه إلى إقامة رابطة واحدة بين سكان المعمورة، عبر الهيمنة على العلم بإخضاعه لسلطان التقنية والهيمنة على الاتصال بإخضاعه لسلطان الشبكة والهيمنة على التنمية

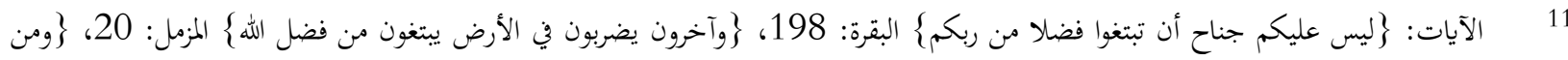

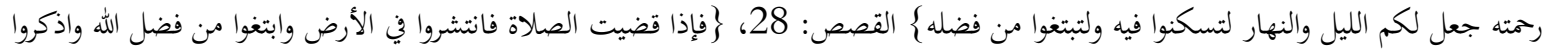


بإخضاعها لسلطان الاقتصاد؛ فكان أن وقعت في اعوجاجات ثلاثة:تقديم الإجراء الآلي على العمل المقصدي، وتقديم المعلومة البعيدة على المعرفة القريبة، وتقديم المنفعة المادية على المصلحة المعنوية.

ولا قدرة للعولمة على تقويم هذه الاعوجاجات بنفسها ومن داخلها، لأها لا تفرز إلا قيما أخلاقية من جنسها، وهذا التقويم يحتاج إلى قيم أخلاقية من غير جنسها، ولا وجود لها إلا في الدين الإلهي، وأحق الأديان هذا التقويم وأقدرها عليه هو الدين الإسلامي، لثبوت خاتَّيَّه القطعي ودخول العولمة في زمنه الأخلاقي.

فمبدأ الاعتبار من مبادئه يقضي بإعادة النظر في المفهومين العلميين: مفهوم "التطبيق التقني للعلم" ومفهوم "البحث العلمي"، فليس كل تطبيق نافع ولا كل بحث مشروع؛ وتكون هذه الإعادة بتقرير تبعية الأسباب في الأشياء للحِكم التي من ورائها وتبعية أحوالها للمآلات التي تنتهي إليها.

أما مبدأ التعارف، فيقضي بإعادة النظر في المفهومين الاتصاليين: مفهوم "الاستزادة غير المحدودة من المعلومات" ومفهوم "المعلومة المجردة"، فليست كل زيادة في المعلومات مطلوبة ولا كل معلومة محايدة؛ وتكون هذه الإعادة الثانية بتقرير تبعية نقل الخبر لفعل المعروف وتبعية العلاقة بين المخبر والمتلقي لاعتراف أحدهما بالآخر. وأما مبدأ ابتغاء الفضل، فيقضي بإعادة في النظر في المفهومين الاقتصاديين: مفهوم "الثنمية الاقتصادية" ومفهوم "المصلحة"، فليست كل تنمية اقتصادية ضرورية ولا كل مصلحة مادية؛ وتكون هذه الإعادة الثالثة بتقرير تبعية الاقتصاد لمقومات التنمية الأخرى وتبعية المنفعة للأفق المعنوي للإنسان.

وهكذا، تكون مسؤولية المسلمين أعظم من أي وقت مضى، لأفم يملكون في دينهم من أسباب التصدي لانخرافات العولمة ما لا يملكه غيرهم، ولأن مسؤوليتهم تقع عليهم أكثر مما تقع على هؤلاء ولو أها ليست منا كسبت أيديهم، وذلك لظهورها في الزمان الأخلاقي الذي حُلقِق لهم دون سواهم، ولا خوف عليهم من زحفها ولا من هولما متى سارعوا إلى النهوض بهذه المسؤولية؛ فهمّة الإنسان أكبر من أن تقهرها قوة العولمة، وعُدَّةُ المسلم أقوى من أن تقهرها عظمة المسؤولية. 